\title{
Paracelsus, and 500 years of encouraging scientific inquiry
}

\section{Stood for sensitivity to the environmental, social, spiritual, and moral dimensions of health}

Theophrastus von Hohenheim, otherwise known as Paracelsus, is vaguely remembered as an innovative but controversial figure, deserving a place in medical history, but distinctly on the alternative fringe. The 500th anniversary of his birth provides a convenient moment to consider whether he deserves wider recognition.

The well remembered afterdinner speech made in his presidential capacity by the Prince of Wales to the BMA in December 1982 linked the name of Paracelsus with the holistic approach to medicine. 'The prince's intervention prompted the BMA into action and ultimately into a more constructive position on questions relating to complementary medicine..$^{2-4}$ The recent switch of terminology, replacing "alternative" with "complementary," itself indicates a new spirit of tolerance and openmindedness.

Paracelsus's influence on homoeopathy and holistic medicine is genuine, but the paracelsian legacy is much wider. More than any other person Paracelsus prevented the consolidation of the influence of classical medicine and the imposition of galenic orthodoxy by the powerful renaissance establishment.

To underline his break with tradition Paracelsus (a native of Zurich) wrote in the vernacular and adopted a non-academic style accessible to a wide public. The first contest of the scientific revolution was fought by Paracelsus, well ahead of the more famous initiatives of Vesalius and Copernicus. More forcefully than Vesalius, Paracelsus called for the abandonment of galenism and its replacement by a new system of scientific knowledge and medicine based on sound empirical foundations.

His call for a new spirit of experimental investigation was later codified and converted into a more concrete programme by Francis Bacon. Bacon's well known appeal for the intellectual elite to abandon various forms of intellectual "idolatry," including their dependence on classical authority, in favour of the productive methods of the skilled artisan was imitative of Paracelsus.

Also taken from Paracelsus was the idea that the new science and medicine were biblically sanctioned and destined to attain a new level of control over nature. This conception of experimental science and medicine as the divinely appointed arbiter of human destiny provided an enormous impetus to scientific effort and was basic to the ideology of the Royal Society. The authoritative Latin edition of the collected writings of Paracelsus appeared in 1658, four years before the foundation of the Royal Society. The great spate of English translations of Paracelsus also belonged to the $1650 \mathrm{~s}$, confirming that the peak of his influence in England connected with what is arguably the unsurpassed golden age of British science and medicine, coinciding with the formative years of such figures as Boyle, Sydenham, and Willis, all of whom were affected by paracelsian influences. ${ }^{56}$

As in the case of Bacon, the central importance of Paracelsus rests on the general impetus he gave to the reform of science and on the development of a comprehensive religious and ethical framework for scientific and medical endeavour..$^{7.9}$ Unlike Bacon, however, Paracelsus was not writing from the standpoint of a scientific and medical amateur. As a practical clinician he sought to describe the normal and the pathological without resorting to either the abstractions of galenism or the incomprehensible mythological and numerological symbolism of contemporary alchemy. $\mathrm{He}$ turned instead to naturalistic analogies drawn especially from chemistry.

With hindsight this explanatory framework often seems inadequate, inappropriate, and inconsistent. Yet it also provided a basis for the dynamic interpretation of biological processes, leaving room for a high degree of psychosomatic interaction. Regardless of its limitations, the system of Paracelsus seems more satisfactory than the highly regarded but crude reductionist models that came into vogue in later generations.

Of paramount importance were Paracelsus's conception of disease as a specific entity, taking up its residence in localised sites and possessing a distinct natural course, and the hypothesis that a specific remedy could be applied to counteract such an intrusion. This recognisably modern concept of disease was entirely at odds with galenism.

Armed with admittedly provisional hypotheses, Paracelsus explained in naturalistic terms and offered the possibility of relief to conditions that the Galenists treated as incurable, the church identified as demonic possession, or the public treated with fatalistic resignation. Paracelsus made intractable problems such as plague, syphilis, epilepsy, mental disorder, and learning disabilities central to his preoccupations. Although in the case of learning disabilities he accepted that he was dealing with congenital conditions incapable of radical improvement, his regimen called not only for humane 
treatment but also for an appreciation that disabled people deserved special understanding because of their superior spiritual status. ${ }^{10}$

In a similar revolutionary manner Paracelsus confronted the contemporary craze for seeing witchcraft everywhere and

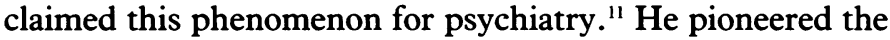
investigation of diseases of mineworkers and in 1520, aged 27 , produced the first monograph ever written on occupational disease. ${ }^{12}$ The longest section of this work dealt with the signs and symptoms of mercury poisoning. This experience laid the foundations for his application of compounds of mercury and other metals for therapeutic purposes. Arguably this advocacy of mercurials for the treatment of syphilis laid the foundations for the success of the paracelsian movement, because the newly arrived scourge of syphilis was the most feared disease of the sixteenth century, occupying a similar position to AIDS in Africa today. The paracelsian mercurials represented one of the small handful of important therapeutic advances made before the present century.

Paracelsus therefore made a significant contribution to medical knowledge across a broad front. He represented a new mood of therapeutic optimism and outlined a scientific approach capable of giving reality to his ambitious aspirations. The new science was guided by his conviction that the "light of nature" endowed the human race with the capacity to attain dominion over nature and, indeed, command over the stars. The twentieth century has witnessed the realisation of these objectives, perhaps even beyond the horizons of Paracelsus's fertile imagination.
Despite all its achievements, modern medicine has failed to capture Paracelsus's sensitivity to the environmental, social, spiritual, and moral dimensions of medical intervention. This outlook was a consequence of his exploitation of the neoplatonic belief of the analogy between the macrocosm and microcosm and his belief that humans were linked with God and nature in a dynamic cosmic order. Modern scientific medicine has of course dispensed with such speculative constructs, but thereby it may also have sacrificed therapeutic insights available to our renaissance predecessors. In this respect orthodox medicine may have placed itself at some disadvantage to its complementary counterparts.

CHARLES WEBSTER Senior Research Fellow

All Souls College,

Oxford OX1 4AL

1 BMA's 150th anniversary council dinner. $B M \mathcal{F} 1983 ; 286: 65$.

2 Alternative medicine [editorial]. $B M \mathcal{H}$ 1983;287:307.

3 BMA. Alternative medicine. London: BMA, 1986.

BMA. Complementary medicine. The BMA guide to good practice. Oxford: Oxford University Press (in press).

Webster C. The great instauration: science, medicine and reform 1626-1660. London: Duckworth 1975 .

6 Webster C. From Paracelsus to Newton: magic and the making of modern science. Cambridge: Cambridge University Press, 1982.

Pagel W. Paracelsus: an introduction to philosophical medicine in the era of the renaissance. Basle: Karger, 1958.

Goldammer K. Paracelsus in neuen Horizonten. Vienna: Verband der Wissenschaftlichen Gesellschaften Österreichs, 1986.

schaften Osterreichs, 1986.
Goldammer K. Der Götlliche Magier und die magierin Natur. Stuttgart: Franz Steiner, 1991.

9 Goldammer K. Der Gottliche Magier und die magierin Natur. Stuttgart: Franz Steiner, 1991.
10 Cranefield PF, Federn W. The begetting of fools: an annotated translation of Paracelsus' De generatione stultorum. Bulletin of the History of Medicine 1967;41:56-74, 161-74.
gention

11 Galdstone I. The psychiatry of Paracelsus. Bulletin of the History of Medicine 1950;24:205-18.

12 Rosner E. Hohenheim's Bergsucht monographie. In: Dilg-Frank R, ed. Kreatur und Kosmos. Internationale Beitrage zur Paracelsus Forschung. Stuttgart: Gustav Fischer, 1981:20-52.

\section{Hypertension and cancer}

\section{Correlation or coincidence?}

Two papers by Fletcher et al (p 622) and Hole et al (p 609) in this week's journal constitute the latest chapter in the slowly unfolding chronicle on hypertension and cancer. Persuasive evidence linking these two conditions first surfaced in $1975,{ }^{3}$ but nearly two decades later their association remains enigmatic.

Given the serious clinical ramifications, most attention has been justifiably directed at determining whether antihypertensive treatments are carcinogenic. Firstly, retrospective studies implicated reserpine in breast cancer, but the drug was later absolved by prospective analyses. ${ }^{34}$ Similarly, limited case-control data suggested an association between use of diuretics and renal cancer, but larger series and the outcomes of randomised clinical trials have not confirmed this. ${ }^{56}$

More recently, the accusing finger has shifted to the $\beta$ blocker atenolol. The Medical Research Council's trial of antihypertensive treatment in elderly people found that death from cancer was nearly twice as common in men receiving atenolol as in men receiving placebo. ${ }^{5}$ This association was not observed in women, and because it was noted in an unplanned subgroup analysis the authors urged that the finding should be interpreted cautiously.

Against this backdrop come this week's studies of hypertension, antihypertensive drugs, and cancer. Both reports constitute post hoc analyses of data on several thousand patients followed up for varying periods at regional hypertension clinics. Cancer rates according to type of antihypertensive treatment are reported, with particular attention being paid to atenolol. Both groups of investigators adjust for age, sex, and current smoking habit, although without more thorough consideration of known risk factors for cancer (for example, past smoking habit, use of alcohol, and occupational exposures), the validity of the results remains in some doubt.

Fletcher and colleagues report that patients receiving atenolol have the same mortality from cancer as those not receiving atenolol.' ${ }^{1}$ Diuretics are also not associated with cancer. Hole and colleagues report the incidence of cancer as well as mortality, and they compare rates observed in hypertensive patients with normative data on incidence from national figures and from a survey in Renfrew and Paisley. ${ }^{6 a}$ Although their abstract states that neither men nor women taking atenolol experienced an increased rate of cancer, subgroup analysis shows that non-smoking men receiving atenolol had a significantly increased risk of dying of cancer (relative risk 1.58). Though this again represents an unexpected finding on subgroup analysis, more than three quarters of men in the Medical Research Council's trial were non-smokers, and one could argue that both studies observed increased cancer mortality in non-smoking men treated with atenolol. Other large clinical trials have not described any increase in cancer after treatment with other $\beta$ blockers, but reporting of such unanticipated outcomes is often incomplete.

Both of the new studies replicate the previously reported association between renal cancer and hypertension. The small number of cases, however, precludes examination of the effects of different antihypertensive drugs, which is important because some epidemiological evidence suggests that the increased rate of renal cancer in hypertensive patients is attributable, at least in part, to their use. ${ }^{78}$ 